Article

\title{
Probabilistic Generalization of a Comprehensive Model for the Deterioration Prediction of RC Structure under Extreme Corrosion Environments
}

\author{
Xingji Zhu ${ }^{1}$, Zaixian Chen ${ }^{1, *}$, Hao Wang ${ }^{2}{ }^{\mathbb{D}}$, Yabin Chen ${ }^{1}$ and Longjun $\mathrm{Xu}{ }^{1,3}$ \\ 1 Department of Civil Engineering, Harbin Institute of Technology at Weihai, Weihai 264209, China; \\ zhuxingji@hit.edu.cn (X.Z.); 14B933032@hit.edu.cn (Y.C.); xulongjun80@163.com (L.X.) \\ 2 Department of Civil Engineering, Southeast University, Nanjing 210096, China; wanghao1980@seu.edu.cn \\ 3 Cooperative Innovation Center of Engineering Construction and Safety in Shandong Blue Economic Zone, \\ Qingdao 266033, China \\ * Correspondence: zaixian_chen@sina.com; Tel.: +86-0631-568-7845
}

Received: 3 July 2018; Accepted: 25 August 2018; Published: 28 August 2018

\begin{abstract}
In some extreme corrosion environments, the erosion of chloride ions and carbon dioxide can occur simultaneously, causing deterioration of reinforced concrete (RC) structures. This study presents a probabilistic model for the sustainability prediction of the service life of RC structures, taking into account that combined deterioration. Because of the high computational cost, we also present a series of simplifications to improve the model. Meanwhile, a semi-empirical method is also developed for this combined effect. By probabilistic generalization, this simplified method can swiftly handle the original reliability analysis which needs to be based on large amounts of data. A comparison of results obtained by the models with and without the above simplifications supports the significance of these improvements.
\end{abstract}

Keywords: reinforced concrete; corrosion; chloride ingress; carbonation; probabilistic; sustainability prediction

\section{Introduction}

The initiation of corrosion is generally due to the penetration of free chloride ions, carbonation, or their combined effect [1-6]. Meanwhile, previous studies also showed that the effect of temperature and humidity on the transport of harmful ions was significant [7-9]. Some works which studied the whole process of reinforcement corrosion indicate that the load-capacity of RC structures would decrease rapidly after steel reinforcements get depassivated [10-14]. As we know, the load-carrying capacity of the entire RC structure reduces seriously only after the extent of corrosion exceeds a certain limit. This characteristic can be easily represented by defining a probability threshold. Therefore, probabilistic analysis for the deterioration of corroded RC structures is very useful for service life sustainability predictions.

The reliability of chloride-induced corrosion was studied in many papers [15-25]. However, the penetration of harmful ions was only considered with a simple diffusion equation, for the sake of simplicity. All of these works did not consider the effect of chloride binding capacity, convection, temperature, and humidity. Meanwhile, the boundary concentration of chloride was only considered as a normal random variable. This means that none of the above-mentioned probabilistic models can be used for RC deterioration assessments under a de-icing salt environment. In that particular case, the chloride concentration on the surface of the concrete should be considered a piecewise function. Therefore, it is more natural and appropriate to use stochastic processes to model the uncertainties of time-dependent boundary conditions in probabilistic analyses. Meanwhile, the probability of 
carbonation-induced corrosion was studied in [26-40]. However, all of these works just predicted the depth of carbonation based on the empirical formula alone.

As we know, chlorides are the dominant deterioration mechanisms in most cases. However, in some extreme corrosion environments, such as at the entrance and exit of various types of offshore tunnels, carbon dioxide pollution and salt spray intrusion are both very serious [31-33]. At some moments of heavy traffic, the rate of carbonation of concrete will be ten times faster than normal [31]. Another more common case occurs on the concrete bridges in cities. Due to the influence of vehicle exhaust, the concrete pavement generally suffers from severe carbonation-induced deterioration. At this point, once de-icing salt is used heavily, severe combined corrosion of concrete will occur. Our previous observations indicated that the service-life of RC structures under these extreme environments will be shortened to less than one-third of the design life [32]. At this time, it is very important to study the deterioration of concrete structures under these special conditions.

Many experiments have shown that the penetration of free chloride ions and moisture are influenced significantly by carbonation [34-43]. However, most chloride- and carbonation-induced corrosion is considered independently in all existing probabilistic analyses [15-30], including the widely recognized FIB model code for service life design [44]. Therefore, we need a more accurate probabilistic model to calculate the reliability of RC structures with combined deterioration under extreme environments. The interaction mechanism of carbonation and chloride ingress was studied recently in other papers of $\mathrm{Zhu}$ et al. [32,33]. The influence mechanism can be summarized as: (1) the reduction in the chloride binding capacity of concrete by carbonation; (2) change in the critical radius of pores and porosity of concrete; (3) release of free chloride ions from bound chloride; and (4) the change in the threshold chloride content. Appendix A shows the mineralogical mechanism of carbonation-induced change of chloride binding capacity and the release of free chloride ions form bound chloride.

A probabilistic generalization for this combined action was presented based on that theoretical model [45]. However, the complexity of that model causes increased computational cost, meaning that the probabilistic study is expensive, and only the Monte Carlo method is applicable. Therefore, the theoretical model will be further simplified, and a series of approaches is presented to simplify the solution procedure and the limit state functions. Meanwhile, a new semi-empirical method is developed specially to swiftly calculate the probability of deterioration under the combined action, when large amounts of data are needed.

Following this introduction, the reliability model for the combined deterioration is reviewed in Section 2. Then, Section 3 provides further simplification by combining the limit state functions to be one for the original probabilistic model. Two simplified approaches for the solution of the comprehensive probabilistic model are given, too. A new semi-empirical method for the approximate reliability study of this combined deterioration is proposed in Section 4. An example is discussed in Section 5, and the conclusion follows in Section 6.

\section{Review of the Reliability Model of Combined Deterioration}

\subsection{Governing Equation and Limit State Functions}

In previous studies [1,46-49], the transport of free chloride ions in concrete is considered as meeting Fick's second law of diffusion. The one-dimensional solution of the partial differential diffusion with Crank's error is widely used. Similarly, the depth of carbonation was interpreted to be linearly proportional to the square root of time. Then, it was used to predict the probability of the carbonation-induced corrosion initiation by comparing with the thickness of the concrete cover [26-30]. However, none of these models can consider the coupling effect of carbonation and chloride attack.

To improve the shortcoming of the analytical one-dimensional probabilistic analysis, a comprehensive probabilistic model of reinforcement corrosion is developed in [45]. The governing equation of the transport of free chloride ions with carbonation can be given by [32] 


$$
\begin{gathered}
\frac{\partial C_{f c}}{\partial t}=\nabla \cdot\left(D_{f c}^{c a r} \nabla C_{f c}\right)+\nabla \cdot\left(C_{f c} D_{h}^{c a r} \nabla h\right)+Q_{r c} \\
\frac{\partial C_{\mathrm{CO} 2}}{\partial t}=\nabla \cdot\left(D_{\mathrm{CO} 2} \nabla C_{\mathrm{CO} 2}\right)-Q_{h}
\end{gathered}
$$

where $C_{f c}$ is the content of free chloride ions ( $\backslash \%$ binder wt.), $Q_{r c}$ is the release rate of free chloride ions at the carbonation interface, $h$ is the humidity, $C_{\mathrm{CO} 2}$ is the $\mathrm{CO}_{2}$ concentration in the pore of concrete, $Q_{h}$ is the consumption rate of hydration product in the reaction process of carbonation, involved $\mathrm{Ca}(\mathrm{OH})_{2}$ and $\mathrm{CSH}$ et al. [32], $D_{f c}^{c a r}, D_{h}^{c a r}$ and $D_{\mathrm{CO} 2}$ are the apparent diffusion coefficients of free chloride ions, humidity and $\mathrm{CO}_{2}$ with the influence of carbonation.

Then, two limit state functions are introduced to calculate the probability of corrosion initiation due to the combined action of chloride ingress and carbonation, i.e.,

$$
\begin{gathered}
g_{1}(\mathrm{x}, t)=\eta(\mathrm{x}, t) C_{f c, t h}-C_{f c}(\mathrm{x}, t) \\
g_{2}(\mathrm{x}, t)=p H(\mathrm{x}, t)-p H_{t h}
\end{gathered}
$$

where $x$ is a vector reflecting the random variables $C_{f c, t h}$ is the threshold chloride content; $\eta(\mathrm{x}, t)=C_{c h, d} /\left[C_{c h, d}\right]_{0}$ is a correction coefficient depending on the degree of carbonation; $C_{c h, d}$ and $\left[C_{c h, d}\right]_{0}$ are the instantaneous and initial concentration of dissolved calcium hydroxide during the process of carbon dioxide intrusion, respectively; $p H(x, t)$ is the instantaneous $\mathrm{pH}$ value; and $p H_{t h}$ is the critical $\mathrm{pH}$ value which can cause the initiation of reinforcement corrosion.

Because the individual action of both agents can cause corrosion initiation, the failure domain under this combined action should be defined as the union of the corrosion domain due to chloride ingress and the corrosion domain due to carbonation, as shown in Figure 1. Then, the probability of corrosion initiation under the combined action $p_{f, c o m b}$ at time $t$ can be given by:

$$
p_{f, \text { comb }}(t)=\int_{g_{1}(\mathrm{x}, t)<0 \text { or } g_{2}(\mathrm{x}, t)<0} f(\mathrm{x}, t) \mathrm{dx}
$$

The stochastic processes with Karhunen-Loeve expansion are used to model the random nature of the environmental parameters varies with exposure time, including, boundary temperature $T_{b}$, boundary humidity $h_{b}$, boundary chloride concentration $C_{f c, b}$ and boundary carbon dioxide $C_{\mathrm{CO} 2, b}$. For detailed information, refer to [45-47].

Corrosion initiation due to chloride ions ingress

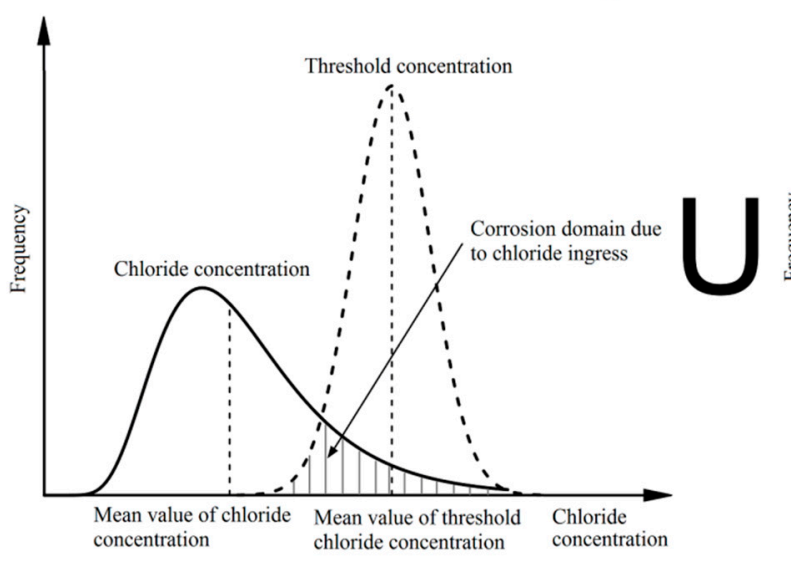

Corrosion initiation due to carbonation

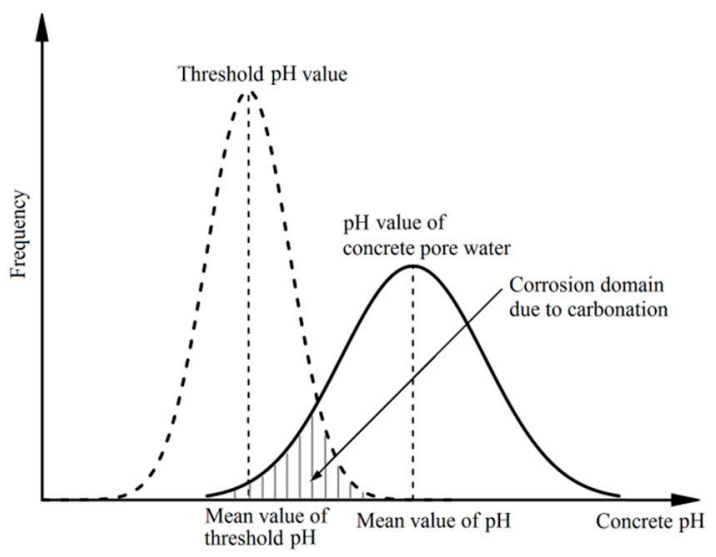

Figure 1. Prediction of corrosion initiation under the combined action. 


\subsection{Reduced Number of Random Variables}

However, the comprehensive coupling model which simulates the combined action of chloride ingress and carbonation is very complex; it contains nine important control equations and more than one hundred parameters [32]. Therefore, the computational cost of that theoretical model is very high. Due to the complexity of the basic theoretical model, each deterministic case that is solved consumes a lot of time in the Monte Carlo method, for an actual problem.

For instance, a beam with fly ash concrete is taken as an example to study its corrosion-induced failure probability in Section 5. That model is divided into 461 2D quadrilateral elements with 536 nodes and 21,516 degrees of freedom. We use a commercial finite element software COMSOL Multiphysics to solve each sample of the deterministic theoretical model. Then, by linking with Matlab, the numerical results obtained by COMSOL are used for the probability calculation.

In a personal computer, it takes approximately $70 \mathrm{~s}$ per computer run of the original basic theoretical model. When we adopt the conventional solution procedure based on the Monte Carlo method, even if only eight of the most sensitive parameters are selected as independent random variables, and all of them are divided as five equal intervals, a computer still needs a very long time to solve this 2D reliability model. Therefore, it is necessary to further simplify the original basic theoretical model and develop some simplified approaches for the solution process of the probabilistic model.

Note that not all of the parameters meaningfully influence the results of the calculation in actual problems. To reduce the computational cost of the probabilistic model, we also reasonably reduce the random variables. Here, a sensitivity analysis is conducted for the 24 most important parameters. The specific analysis process, environmental condition, and concrete composition and reference value are introduced in our previous work [45]. With each key parameter increased and decreased by $20 \%$ of their original value, the tornado diagram of the changes in the initiation time of corrosion is shown in Figure 2.

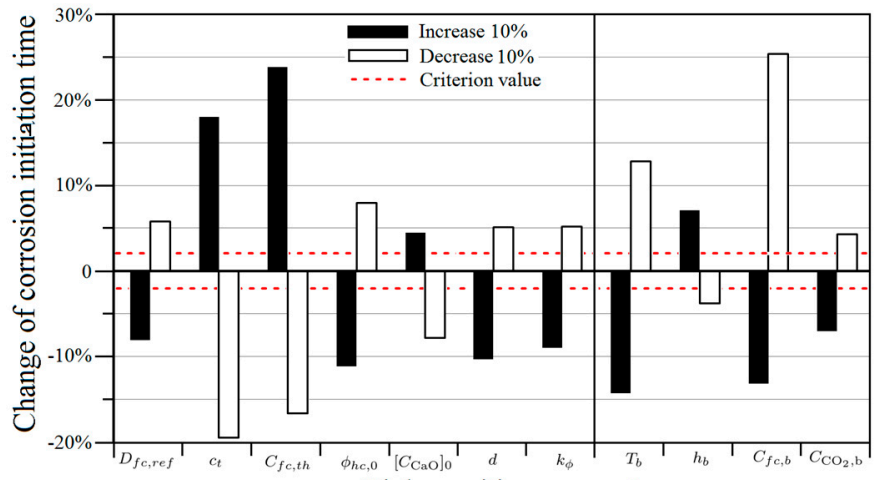

High sensitive parameters

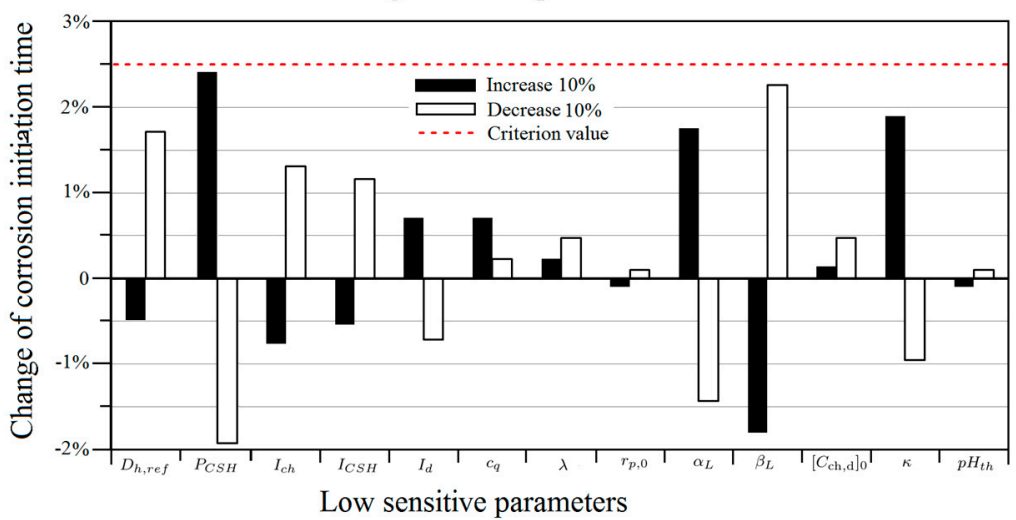

Figure 2. Change of initiation time of corrosion if each key parameter is increased and decreased by $20 \%$. 
The parameters are sorted from high to low sensitivity as follows: $C_{f c, t h}, c_{t}, \varphi_{h c, 0}, d, k_{\varphi}, D_{f c, r e f}$, $\left[C_{C a O}\right]_{0}, P_{C S H}, \beta_{L}, \alpha_{L}, \kappa, D_{h, r e f}, I_{c h}, I_{C S H}, I_{d}, c_{q}, \lambda_{q},\left[C_{c h, d}\right]_{0}, r_{p, 0}$, and $p H_{t h}$. These all are the parameters in our proposed comprehensive theoretical model for predicting the combined deterioration of chloride ingress and carboantion. The meaning and explanation for those parameters can be found in the literature [32]. Parameters $C_{f c, b}, C_{\mathrm{CO} 2, b}, T_{b}$, and $h_{b}$ are used to determine the boundary conditions in all the cases; their sensitivity is not involved in the comparison and sorting.

In this study, only seven key parameters are selected as random variables for probabilistic analysis. These seven were selected based on the test results for one-way sensitivity, including $C_{f c, t h}, c_{t}, \varphi_{h c, 0}, d$, $k_{\varphi}, D_{f c, r e f},\left[C_{\mathrm{CaO}}\right]_{0}$. Compared to a case that considers all 20 parameters to be random variables, it can be found that computational cost based on the conventional Monte Carlo method is reduced by a factor greater than 200 million.

\section{Other Further Improvements for the Probabilistic Model of Combined Durability}

\subsection{Single Limit State Function}

Because there are two limit state functions in the original probabilistic model, we cannot use other simple solution methods to solve the original model aside from the complicated Monte Carlo method. Here, a step function $\beta(x, t)$ is introduced to reflect the contribution of carbonation on the corrosion initiation, instead of a separate limit state function. Then, Equations (3) and (4) are integrated to be one limit state function, i.e.,

$$
\begin{gathered}
g_{3}(\mathrm{x}, t)=\beta(\mathrm{x}, t) \eta(\mathrm{x}, t) C_{f c, t h}-C_{f c}(\mathrm{x}, t) \\
\beta(\mathrm{x}, t)=\left\{\begin{array}{lll}
1 & \text { for } & p H(\mathrm{x}, t)-p H_{t h}>0 \\
0 & \text { for } & p H(\mathrm{x}, t)-p H_{t h} \leq 0
\end{array}\right.
\end{gathered}
$$

Furthermore, we found that the value of $\beta(\mathrm{x}, t)$ is highly coincident with the value of $\eta(\mathrm{x}, t)$. Therefore, $\beta(\mathrm{x}, t) \times \eta(\mathrm{x}, t)$ can be directly replaced by $\eta(\mathrm{x}, t)$, for simplicity. Then, the failure probability under the combined deterioration can be further simplified and adjusted as:

$$
p_{f, c o m b}(t)=\int_{g_{1}(x, t)<0} f(x, t) \mathrm{dx}
$$

With this simplification, it is possible to use of other analytical methods, such as the response surface method, to solve this probabilistic model.

\subsection{Simplification for the Algorithm of Conventional Solution Procedure}

The computational cost of the previous method is still very expansive, even when the random variables were reduced and the original two limit state functions were combined. Here, a simplification method for the solution procedure of the probabilistic model is also provided. This method was firstly proposed by Bazant in [48]. In the process of Latin hypercube sampling, all of the random variables are divided as $n$ intervals. During the solving procedure, only one sample is randomly selected from the sample array of each random variable and used in one computer run. In this simplified method, the total times of runs for the theoretical deterministic models are the divided intervals of the random variables $n$.

\subsection{Response Surface Method}

In some actual problems, maybe there are only a few random variables have different mean values and variances, such as some concrete components with different mix proportions in the same environment. Then, it is not necessary to run the expansive Monte Carlo method to solve individual problems. Instead, the response surface model can be adopted. For a set of models in which only a few random variables differ, this response surface method will greatly simplify the calculation process. 
According to the sampling points of primary random variables, the Monte Carlo result can be fitted and converted to the sample space of a response surface model. Based on this response surface result, the new probabilities of corrosion initiation in other cases can be easily obtained by changing the mean values. The calculation procedure is as follows:

1. The probability of corrosion initiation of a reference specimen is calculated using the Monte Carlo method.

2. The Monte Carlo result for the above reference specimen is used to build a response surface.

3. By changing the mean value of reach random variable, the probabilities of corrosion initiation in other specimens can be calculated by the above mentioned response surface.

\section{Semi-Empirical Approach for the Probabilistic Study of Combined Durability}

\subsection{Concentration Distribution of Free Chloride ions Considering Carbonation}

Here, we also provide a simple semi-empirical method for this combined deterioration problem. Except for the reliability analysis, its simple equations are also particularly suitable for some special circumstances of the application, such as the compilation of design specifications. According to the coupling mechanism of carbonation and chloride ingress [32] and the chemical reaction mechanism of carbonation $[49,50]$, we believe that the influence of chloride ions concentration for the rate of carbonation reaction is negligible. The classic expression of carbonation depthwith $\sqrt{t}$ is still applicable in this combined durability problem.

Here, a partial carbonated depth (carbonation-process zone) is introduced to optimize Papadakis' analytical formula [49], i.e.,

$$
c_{c a r}=\left\{\begin{array}{cl}
0 & \text { for } t \leq \frac{c_{p a r}^{2}\left[C_{\mathrm{CaO}}\right]_{0}}{2 D_{\mathrm{CO} 2} \mathrm{C}_{\mathrm{CO} 2, b}} \\
\sqrt{\frac{2 D_{\mathrm{CO} 2} \mathrm{CO}_{\mathrm{CO}, b} \cdot t}{\left[C_{\mathrm{CaO}}\right]_{0}}} & \text { for } t>\frac{c_{p a r}^{2}\left[C_{\mathrm{CaO}}\right]_{0}}{2 D_{\mathrm{CO} 2} \mathrm{C}_{\mathrm{CO} 2, b}}
\end{array}\right.
$$

where $c_{c a r}$ and $c_{p a r}$ are the fully and partial carbonated depth.

Previous studies have shown that the reaction rate of carbon dioxide with $\mathrm{Ca}(\mathrm{OH})_{2}$ is much faster than with CSH and Friedel's salt. That means that the release phenomenon of free chloride ions from the Friedel's salt should be mainly after $\mathrm{Ca}(\mathrm{OH})_{2}$ is completely consumed by carbon dioxide. Therefore, the critical degree of carbonation corresponding to this moment is significantly meaningful for the combined deterioration caused by chloride with carbonation. Here, the partial carbonated zone is defined as the degrees of carbonation in the following range:

$$
1-P_{C S H} \leq \alpha_{c}<1
$$

By analyzing the numerical results and experimental data in $[32,34,36,38]$, it shows that the value of $c_{\text {par }}$ depends on the diffusion coefficient of carbon dioxide. This is determined by the mechanism of this partial carbonation phenomenon. If carbon dioxide is transported too fast, the calcium hydroxide and CSH at the reaction interface cannot absorb it completely in time. Then, part of the carbon dioxide passes through the interface and continues to transport to the interior of the concrete. Its formula can be fitted as a cubic polynomial function, i.e.,

$$
c_{p a r}=0.0158 \bar{D}^{3}-0.3702 \bar{D}^{2}+36656 \bar{D}+5.945 \text { for } 0.1 \leq \bar{D} \leq 10
$$

where $\bar{D}=D_{\mathrm{CO} 2} / D_{\mathrm{CO} 2}^{r e f}$ is a dimensionless parameter, $D_{\mathrm{CO} 2}^{r e f}=1 \times 10^{-8} \mathrm{~m}^{2} / \mathrm{s}$ is a reference value for the diffusion coefficient of $\mathrm{CO}_{2}$.

Then, we can decouple the combined effect of carbonation and chloride ingress with a semi-empirical model. The transport of free chloride ions is considered as a separate diffusion 
phenomenon. The completely and partial carbonated zones of concrete are both removed, and the front surface of carbonation is reset as the new boundary for the transport of chloride ions into the internal concrete.

Note that the value of the new boundary condition is also changed because of the carbonation-induced release of free chloride ions. It can be regarded as a linear relationship with the depth of carbonation. The slope of this line can be determined by the mixture proportions of concrete. The theoretical mechanism of that semi-empirical approach is as follows: generally, the depth of carbonation interface is very small and close to the concrete boundary; once a large number of free chloride ions are released at the carbonation interface, a rapid reverse diffusion process will be formed from the carbonation interface to the concrete boundary; and, the peak value of chloride concentration at the carbonation interface is only related to the mineralogical characteristic of concrete and the diffusion rate of chloride ions.

According to large amounts of data, the slope of the linear change of chloride concentration in the carbonated concrete zone, $\beta_{c}$, can be fitted as:

$$
\beta_{c}=-0.004 f_{c a r}^{3}+0.048 f_{c a r}^{2}-0.147 f_{c a r}+0.201 \text { for } 1.5 \leq f_{c a r} \leq 5
$$

for the ordinary Portland Concrete, and

$$
\beta_{c}=-0.009 f_{\text {car }}^{3}+0.089 f_{\text {car }}^{2}-0.340 f_{\text {car }}+0.399 \text { for } 1.5 \leq f_{c a r} \leq 5
$$

for fly ash concrete; where $f_{c a r}$ is the comprehensive influence function of carboantion for the apparent diffusion coefficient of free chloride ion, and its estimated method can be found in [32]. Here, the unit of carbonation depth should be taken as centimeters $(\mathrm{cm})$.

Then, a semi-empirical formula for predicting the chloride concentration considering the effect of carbonation can be expressed as:

$$
C_{f c}(y)=\left(1+\beta_{c} \cdot y\right) C_{f c, b}
$$

for $y \leq c_{c a r}+c_{p a r} ;$ and

$$
C_{f c}(y)=C_{f c, 0}+\left[\left(1+\beta_{c} \cdot y\right) C_{f c, b}-C_{f c, 0}\left[1-\operatorname{erf}\left(\frac{y-c_{c a r}-c_{p a r}}{2 \sqrt{D_{f c, a p p} \cdot t}}\right)\right]\right.
$$

for $y>c_{c a r}+c_{\text {par }}$; where $y$ shows the position of the calculating point, and $C_{f c, 0}$ is the initial condition for the chloride concentration.

The advantage of this semi-empirical method is that the formula of chloride concentration distribution considering the effect of carbonation can be obtained directly, instead of solving the complex and complicated partial differential equations. This will enable the engineers and designers to directly use the simple expression function to predict the combined deterioration of structures.

\subsection{Experimental Verification and Comparison with the Comprehensive Combined Model for the Semi-Empirical Solution}

Here, an alternating test of carboantion and chloride penetration is used to verify this proposed semi-empirical solution [38]. In this test, three Ordinary Portland concrete with different mix proportions are subjected to carbonation for three days by placing in a carbonation chamber. These specimens are named as D-1, D-2, and D-3. For D-1, D-2, and D-3, the vaules of $w / b$ are 0.45 , $0.50,0.55$, respectively; and the vaules of $a / b$ are $0.45,0.50,0.55$, respectively. Before the alternating test, three Ordinary Portland concrete specimens have been used to test the diffusion coefficient of free chloride ions without carbonation. For D-1, D-2, and D-3, their apparent chloride diffusion coefficients are $3.8 \times 10^{-12}, 4.5 \times 10^{-12}$, and $5.6 \times 10^{-12} \mathrm{~m}^{2} / \mathrm{s}$, respectively. 
Then, the volume fraction of $\mathrm{CO}_{2}$ was set to be $5 \%$, and the temperature and humidity were also set to be constants, $20{ }^{\circ} \mathrm{C}$ and $65 \%$, respectively, for the testing chamber. After three days of carbonation, those specimens are then placed in a $\mathrm{NaCl}$ solution with $0.5 \mathrm{M}$. A year later, these two procedures were alternately carried out 120 times.

The distribution of free chloride ions from the alternating test, the comprehensive combined model, and the proposed semi-empirical solution, are shown and compared in Figure 3. It can be found that the peak value of chloride ions content appeared on the carbonation interface, rather than the boundary surface, which is due to the carboantion-induced release of free chloride ions from the bound chloride. The results calculated by the semi-empirical solution are close to the alternating experimental results and the comprehensive combined numerical results.

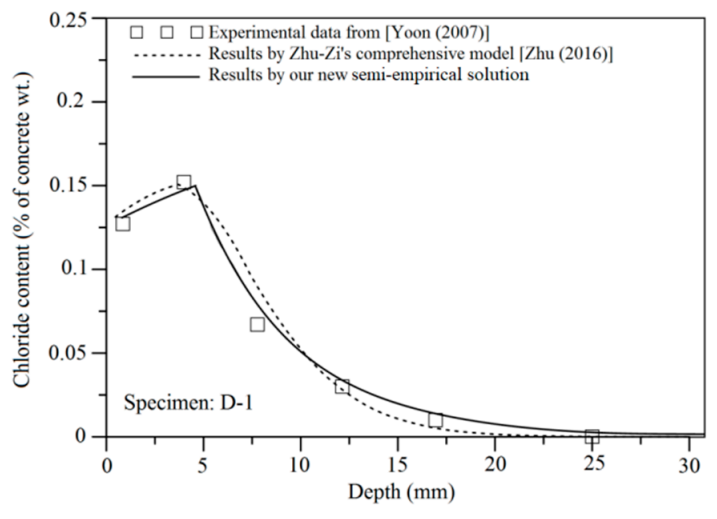

(a)

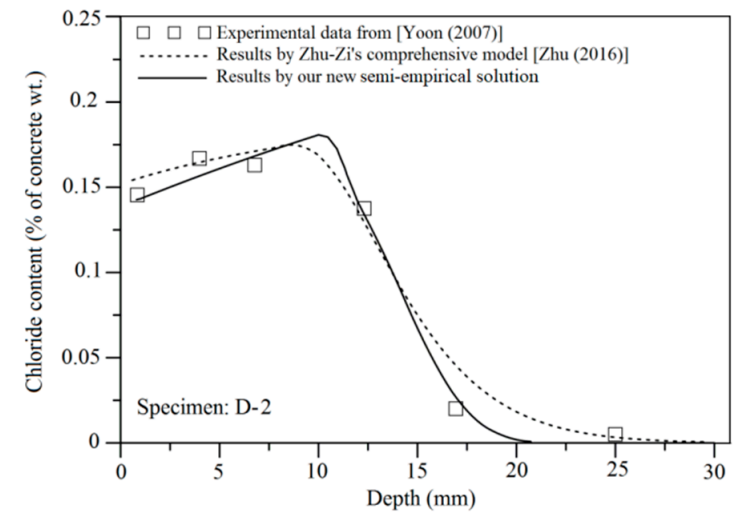

(b)

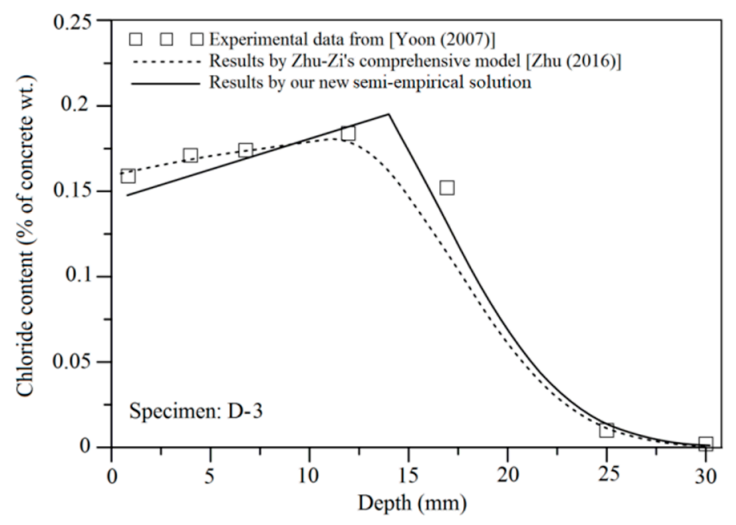

(c)

Figure 3. Distribution of the chloride ions for (a) D-1, (b) D-2, and (c) D-3.

\subsection{Probability Calculation}

According to above-mentioned semi-empirical formulae, the beginning time of corrosion is defined as when the chloride content around the steel rebar exceeds the threshold concentration, or the length of $c_{c a r}+c_{p a r}$ larger than the thickness of concrete cover. Then, the limit state functions is formulated by:

$$
\begin{gathered}
g_{4}(\mathrm{x}, t)=\gamma(\mathrm{x}, t) C_{f c, t h}-C_{f c}(\mathrm{x}, t) \\
g_{5}(\mathrm{x}, t)=c_{t}-c_{c a r}(\mathrm{x}, t)-c_{p a r}(\mathrm{x}, t)
\end{gathered}
$$

where $\gamma(x, t)$ is a dimensionless parameter reflecting the carbonation-induced decrease of the threshold value of chloride concentration. 
As we know, the new value of chloride threshold content depends on the content of calcium hydroxide. The front of the partial carbonated zone should be taken as the interface. In the range of carbonation-process zone, the change of $\gamma(x, t)$ is assumed as linear, for simplicity. Then, $\gamma(x, t)$ can be formulated as:

$$
\gamma(\mathrm{x}, t)=\left\{\begin{array}{ccc}
0 & \text { for } & y \leq c_{\text {car }}(\mathrm{x}, t) \\
\frac{1}{c_{\text {par }}(\mathrm{x}, t)}\left[y-c_{c a r}(\mathrm{x}, t)\right] & \text { for } & c_{c a r}(\mathrm{x}, t)<y \leq c_{\text {car }}(\mathrm{x}, t)+c_{\text {par }}(\mathrm{x}, t) \\
1 & \text { for } & y>c_{\text {car }}(\mathrm{x}, t)+c_{\text {par }}(\mathrm{x}, t)
\end{array}\right.
$$

Similar to the discussion in Section 3.2, the contribution of carbonation on the initiation of corrosion also has been reflected in the parameter $\gamma(\mathrm{x}, t)$. Then, $g_{5}(\mathrm{x}, t)$ can be ignored. The probability of this combined deterioration should be approximately given as:

$$
p_{f, \text { comb }}(t)=\int_{g_{4}(\mathrm{x}, t)<0} f(\mathrm{x}, t) \mathrm{dx}
$$

\section{Illustrative Example and Parametric Study}

\subsection{Problem Description}

A concrete beam with $300 \mathrm{~mm} \times 500 \mathrm{~mm}$ is used for the parametric study. For the concrete, we assume that the $a / b=4, w / b=0.45$, and $F A=10 \%$. Four steel reinforcements with $22 \mathrm{~mm}$ are set in the bottom of this beam. It is assumed that this beam is under severe salt fog environment. $T_{b, \max }=30^{\circ} \mathrm{C}$ and $T_{b, \min }=-10^{\circ} \mathrm{C}$ are defined as the maximum and minimum mean values of environmental temperature, with the correlation length 1 year. $h_{b, \max }=80 \%$ and $h_{b, \min }=70 \%$ are defined as the maximum and minimum mean values of environmental relative humidity, with the correlation length 0.001 year. The effect of saturation on the transport rates of chloride and carbon dioxide is taken into account in their diffusion coefficients by a correction function of relative humidity. Table 1 summarizes the parameter characteristics of random variables for this illustrative example, as suggested by our previous work [32,45].

Table 1. Parameter characteristics of random variables for this illustrative example.

\begin{tabular}{cccc}
\hline Variable & Mean Value & COV & Distribution \\
\hline$C_{f c, b}$ & $0.75 \%$ binder w. t. & 0.2 & Log-Normal \\
$C_{C O 2, b}$ & $0.02 \mathrm{~mol} / \mathrm{m}^{3}$ of pore air & 0.1 & Normal \\
$C_{f c, t h}$ & $0.4 \%$ binder w. t. & 0.2 & Normal \\
$c_{t}$ & $40 \mathrm{~mm}$ & 0.2 & Normal \\
$D_{f c, r e f}$ & $6.5 \times 10^{-12} \mathrm{~m}^{2} / \mathrm{s}$ & 0.2 & Log-Normal \\
$\varphi_{h c, 0}$ & 0.5 & 0.3 & Normal \\
{$\left[C_{C a O}\right]_{0}$} & $3000 \mathrm{~mol} / \mathrm{m}^{3}$ of concrete & 0.05 & Normal \\
$d$ & 0.9 & 0.05 & Normal \\
$k_{\varphi}$ & 0.2 & 0.1 & Normal \\
\hline
\end{tabular}

For the prediction of corrosion initiation of steel reinforcement, previous study indicated that numerous parameters can affect the threshold concentration of chloride ions, and many of them are interrelated [51]. This leads to that the overall trends are not visible for the changing of threshold chloride content. Among so many factors, the influence of the steel-concrete interface is considered the most significant [52-56]. In this example, the threshold chloride content is defined as the chloride content required for depassivation of the steel. The ribbed steel bars are taken as the reinforcements. Some pores exist between reinforcement and concrete due to the low workability. The reinforcement and the surrounding concrete are always in the tension state. All these assumptions mean that the threshold chloride content should take a small value, as given in Table 1. 


\subsection{Result Discussion}

\subsubsection{Probability}

The failure probabilities of corrosion-induced deterioration due to the combined action, penetration of chloride and carbonation calculated by our model can be found in Figure 4 . A comparison of Figure $4 a$ with Figure $4 b, c$ shows that the corrosion-induced failure probability considering the influence of carbonation is significantly larger than the probability without considering carbonation.

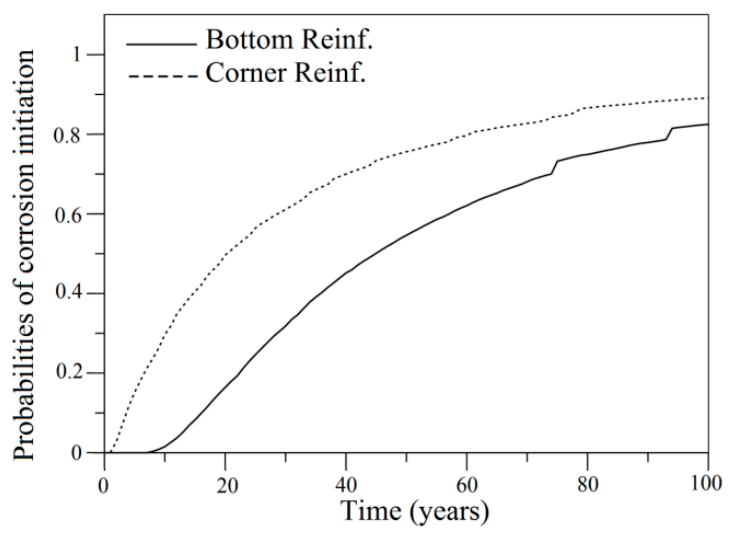

(a)

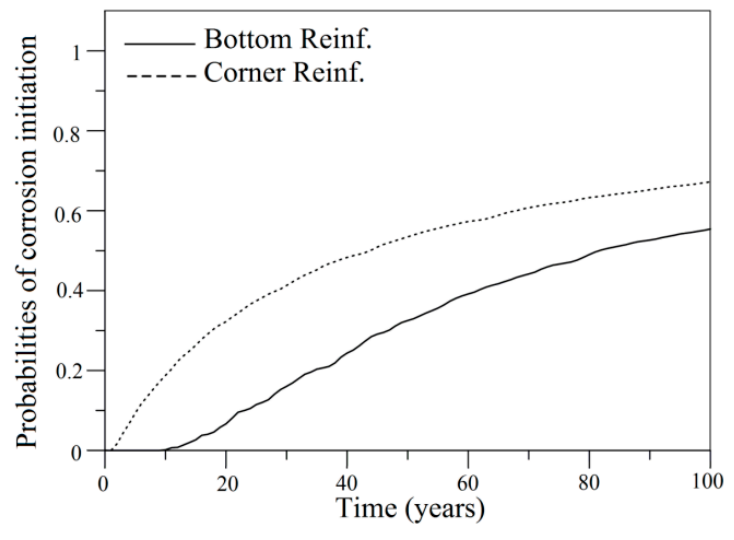

(b)

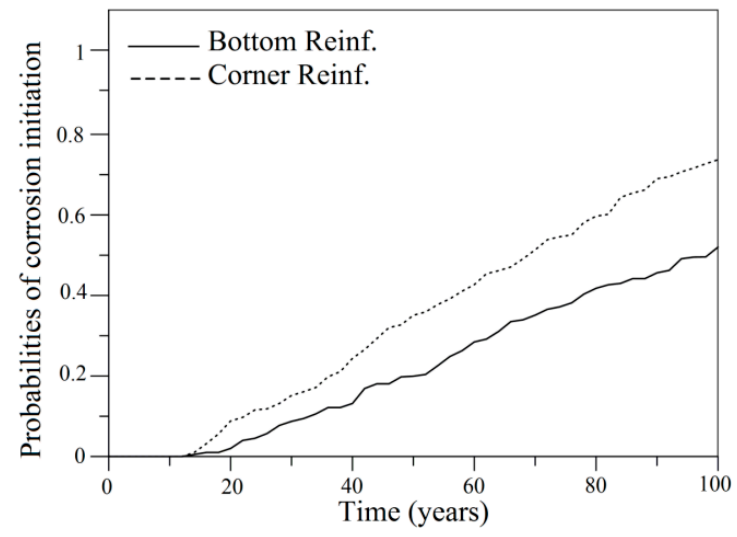

(c)

Figure 4. Probability of corrosion initiation calculated by our model (a) due to the combined action of chloride penetration and carbonation, and (b) only due to the ingress of chloride, and (c) only due to the carbonation.

\subsubsection{Effect of Reducing Limit State Functions}

The probabilities with and without reducing the limit state functions are both shown in Figure 5. It can be seen that the results considering this simplification method are almost identical to the original results. This indicates that the method provided in Section 3.1 is feasible for this comprehensive probabilistic model. 


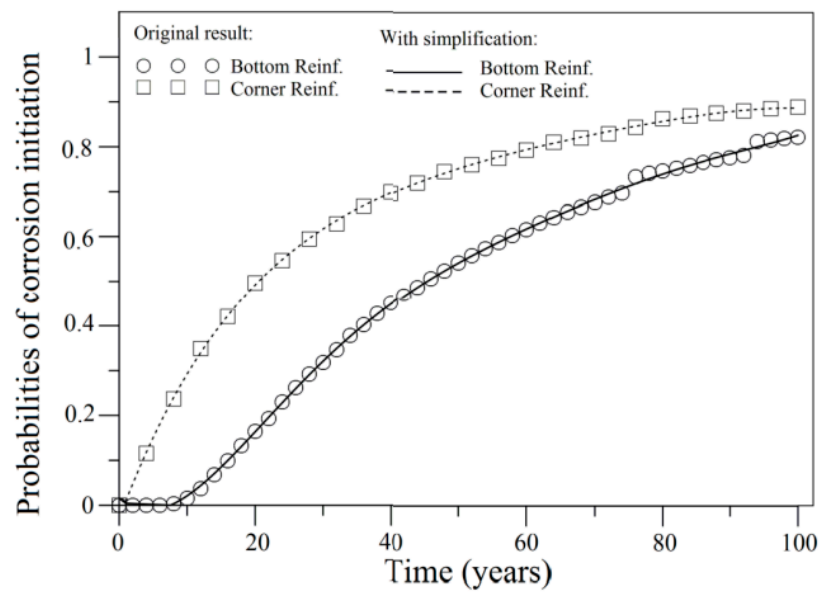

Figure 5. Probabilities with and without the reduction of limit state functions for the bottom reinforcement and the corner reinforcement.

\subsubsection{Effect of Simplified Solution Procedure}

The comparison of corrosion initiation probabilities with and without the simplified solution procedure are shown in Figure 6. In the simplified approach, all of the random variables is divided into 1000 intervals by the Latin hypercube sampling. It was found that the corrosion-induced failure probabilities calculated by the conventional solution procedure, and the method with simplification, are close. Here, an average error, $e$, for checking the difference between corrosion probabilities with and without this simplification is introduced here, and its calculation equation is defined in Appendix B. It is found that the average error is 0.0124 and 0.0254 for the bottom reinforcement and the corner reinforcement, respectively. This accuracy is acceptable for the reliability analysis of a concrete durability problem.

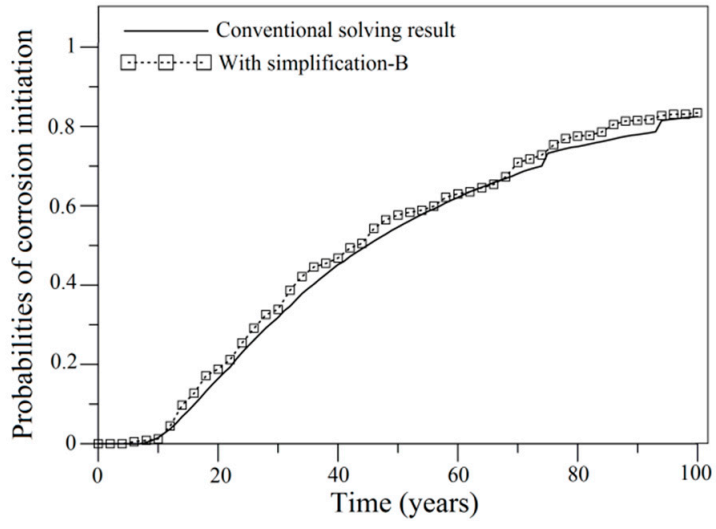

(a)

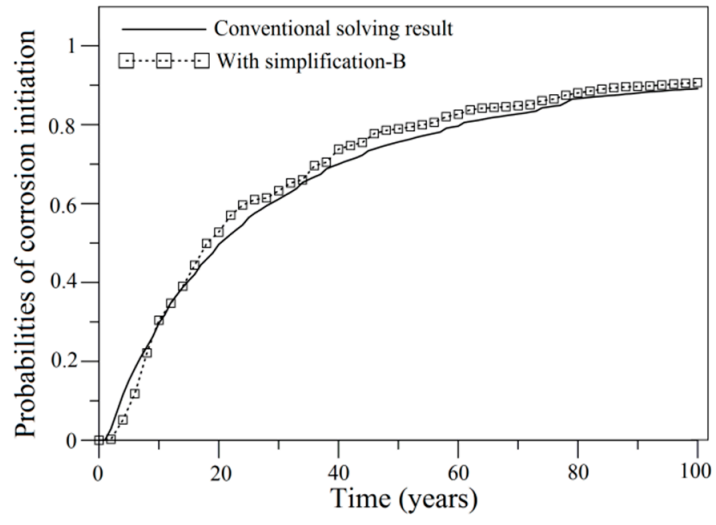

(b)

Figure 6. Corrosion-induced failure probabilities with and without the simplification for solution procedure for the (a) bottom and (b) corner reinforcement.

\subsubsection{Application of the Response Surface Method}

Here, three fly ash concrete and three ordinary Portland concrete sections are used to explain the application of the above mentioned response surface method in the Section 3.3, and verify its accuracy. Their mix proportions are given in Table 2. They are applied to the estimation of parameters for the theoretical model. The mean values of random variables of each specimen are calculated according 
to [32]. The results from the FAC-1 specimen calculated by the Monte Carlo method are taken to build the reference response surface.

The probabilities of the corrosion initiation obtained by the Monte Carlo method and the response surface method are shown and compared in Figure 7. It shows that the results calculated by these two methods closely concur. The average error is $0.0120,0.0139,0.0343,0.0345$, and 0.0285 for specimens OPC-1, OPC-2, OPC-3, FAC-2 and FAC-3, respectively. However, the amount of calculation will be cut by several orders of magnitude if this response surface method is obtained instead of the conventional Monte Carlo method.

Table 2. Mix proportions of concretes.

\begin{tabular}{ccccccc}
\hline \multirow{2}{*}{ Mix Proportions } & \multicolumn{7}{c}{ Specimen } \\
\cline { 2 - 7 } & FAC-1 (Ref.) & OPC-1 & OPC-2 & OPC-3 & FAC-2 & FAC-3 \\
\hline$w / b$ & 0.45 & 0.35 & 0.35 & 0.55 & 0.45 & 0.45 \\
$a / b$ & 4 & 4 & 6 & 4 & 4 & 4 \\
$F A$ & 0.1 & 0 & 0 & 0 & 0.2 & 0.3 \\
\hline
\end{tabular}
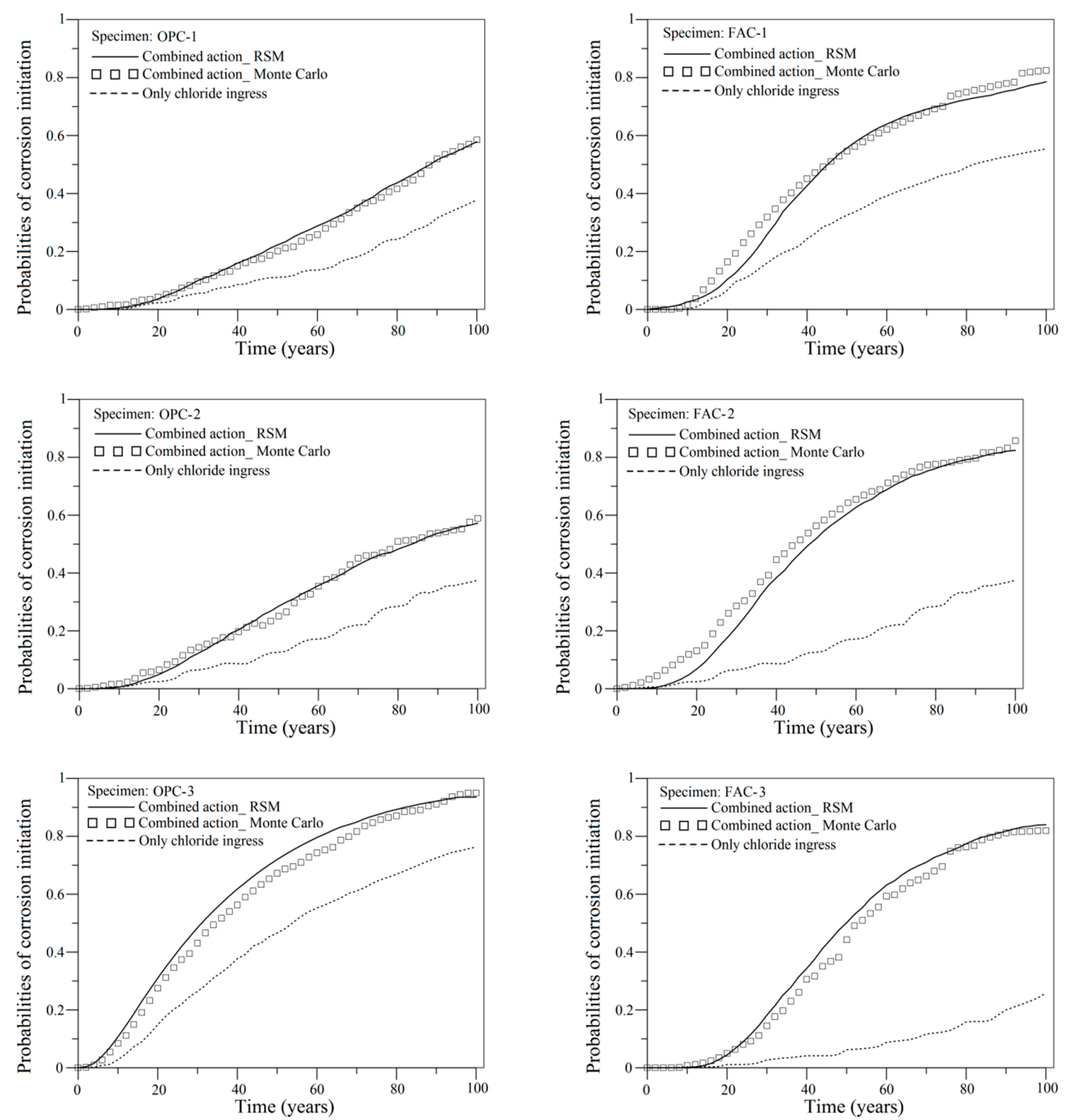

Figure 7. Comparison of the Monte Carlo result and the response surface result for concrete specimens with different mix proportions. 


\subsubsection{Discussion for the Semi-Empirical Probabilistic Model}

The accuracy and error calculated by the semi-empirical probabilistic method is discussed in this section. The parameter characteristics of the selected random variables in the study with semi-empirical method is shown in Table 3. Here, the COVs of $\beta_{c}$ and $c_{p a r}$ are fitted by the numerical results of the comprehensive model. The range of each random variable is also divided as five intervals for Latin hypercube sampling.

The probabilities obtained by the comprehensive model and the proposed semi-empirical method are compared in Figure 8. It shows that the probability curves obtained by these two approaches are very close. The average error is about 0.049 ; this can meet the needs of the accuracy for the actual project.

Table 3. Parameter characteristics of the selected random variables in semi-empirical probabilistic study.

\begin{tabular}{cccc}
\hline Variable & Mean Value & COV & Distribution \\
\hline$C_{f c, b}$ & $0.75 \%$ binder w. t. & 0.2 & Log-Normal \\
$C_{C O 2, b}$ & $0.02 \mathrm{~mol} / \mathrm{m}^{3}$ of pore air & 0.1 & Normal \\
$C_{f c, t h}$ & $0.4 \%$ binder w. t. & 0.2 & Normal \\
$c_{t}$ & $40 \mathrm{~mm}$ & 0.2 & Normal \\
$D_{f c, r e f}$ & $6.5 \times 10^{-12} \mathrm{~m}^{2} / \mathrm{s}$ & 0.2 & Log-Normal \\
$D_{C O 2}$ & $3 \times 10^{-8} \mathrm{~m}^{2} / \mathrm{s}$ & 0.2 & Log-Normal \\
{$\left[C_{C a O}\right]_{0}$} & $3000 \mathrm{~mol} / \mathrm{m}^{3}$ of concrete & 0.05 & Normal \\
$\beta_{c}$ & 0.15 & 0.1 & Normal \\
$c_{p a r}$ & $15 \mathrm{~mm}$ & 0.05 & Normal \\
\hline
\end{tabular}

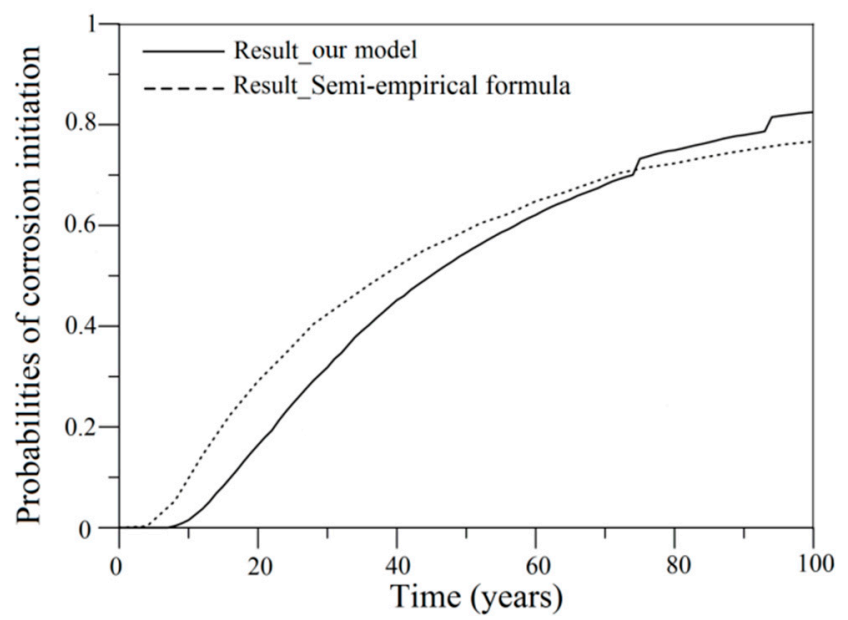

Figure 8. Corrosion-induced failure probabilities calculated by the comprehensive model and the proposed semi-empirical method.

\subsubsection{Comparison with the Conventional One-Dimensional Solution}

The failure probabilities of corrosion-induced deterioration obtained by our model and the widely used analytical one-dimensional method are compared in Figure 9. We can find that the difference of these probability results are significant. This indicates that the influence of the uncertainty of chloride binding capacity, convection, temperature, and humidity should be considered in the probabilistic analysis for a more accurate result. Only using the analytical one-dimensional simplified method to estimate the reliability of the durability of reinforced concrete structure is not rigorous for some cases. 


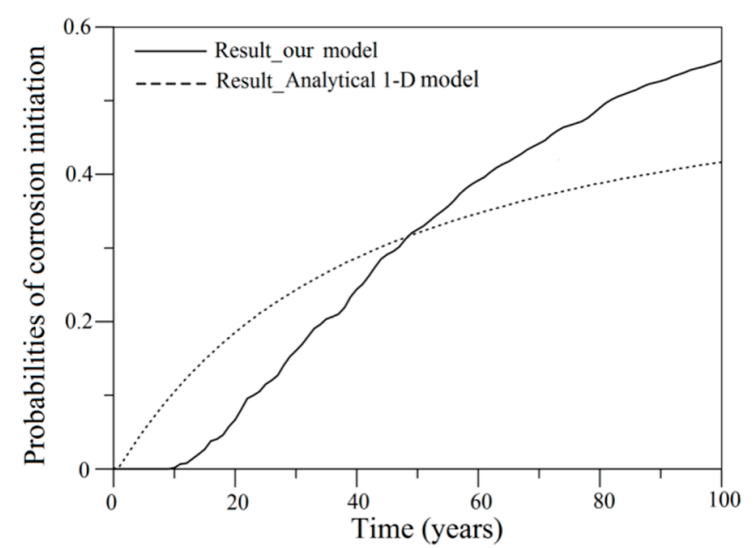

(a)

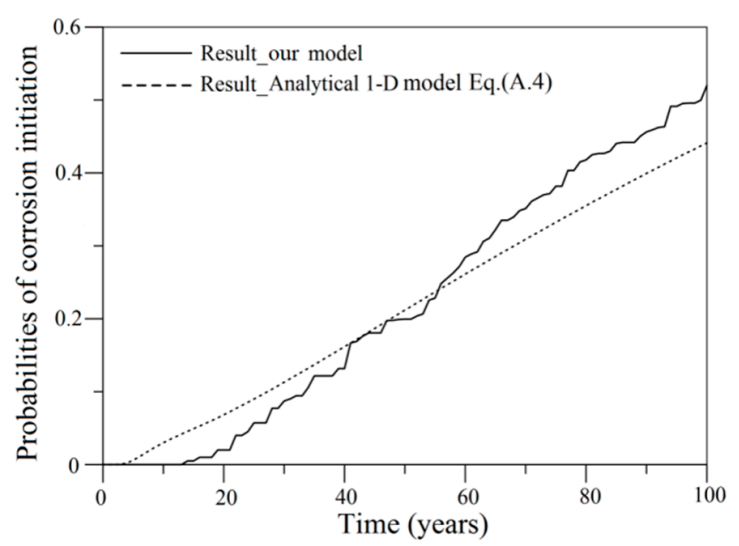

(b)

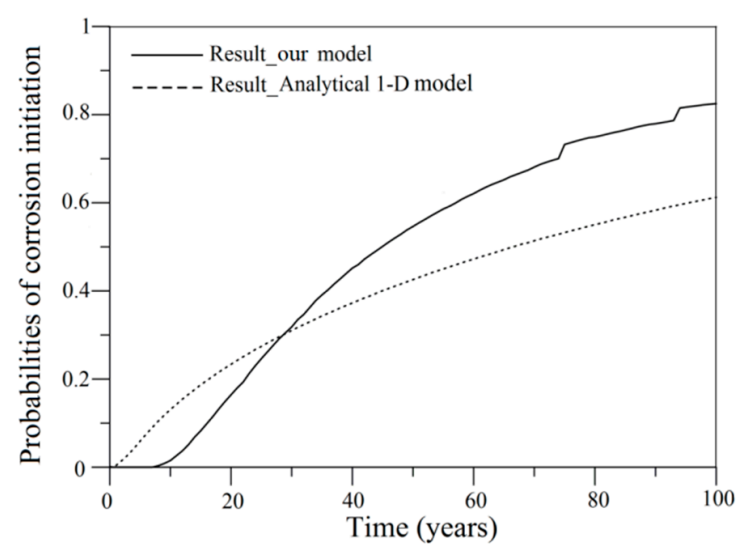

(c)

Figure 9. Corrosion-induced failure probabilities obtained by the comprehensive model and the conventional one-dimensional solution under the (a) penetration of free chloride ions, (b) carbonation, and (c) their combined effect.

\section{Conclusions}

1. A comprehensive model is reviewed to calculate the reliability of corrosion deterioration due to carbonation, chloride penetration, and their combined effect.

2. Two simplified approaches for the solution procedure of this probabilistic model are provided.

3. A semi-empirical method is developed to approximately predict the concentration distribution of chloride ions, and swiftly calculate the probability of combined deterioration.

4. Comparison to the original non-simplified model shows that all of these improved approaches can greatly simplify the computational cost, and that the accuracies are acceptable.

Author Contributions: Conceptualization and Methodology, X.Z.; Validation, X.Z. and L.X.; Resources, Z.C.; Writing-Original Draft Preparation, X.Z. and Z.C.; Writing-Review \& Editing, Y.C. and H.W.

Funding: This work was financially supported by the Natural Science Foundation of Shandong Province (No. ZR2018BEE044), and the National Natural Science Foundation of China (No. 51678199, 51578151, 51678208). We also appreciates the support of the Major Program of Mutual Foundation of Weihai City with Harbin Institute of Technology (Weihai).

Conflicts of Interest: The authors declare no conflict of interest. 


\section{Appendix A. Mechanism of Chemical Link between Carbonation and Chloride Movement}

With the ingress of free chloride ions, the Friedel's salt (bound chloride) is formed in concrete. That chemical reaction process can be depicted by

$$
\mathrm{Ca}_{4} \mathrm{AlH}_{6}+\mathrm{CaCl}_{2}+\mathrm{H}_{2} \mathrm{O} \rightarrow 3 \mathrm{CaO} \cdot \mathrm{Al}_{2} \mathrm{O}_{3} \cdot \mathrm{CaCl}_{2} \cdot 10 \mathrm{H}_{2} \mathrm{O}
$$

Noted that the process of carbonation is much slower than the movement of chloride. Once carbon dioxide comes into contact with the formed Friedel's salt, free chloride ions will be released at the carbonation interface with the following chemical reaction

$$
3 \mathrm{CaO} \cdot \mathrm{Al}_{2} \mathrm{O}_{3} \cdot \mathrm{CaCl}_{2} \cdot 10 \mathrm{H}_{2} \mathrm{O}+3 \mathrm{CO}_{2} \rightarrow 3 \mathrm{CaCO}_{3}+2 \mathrm{Al}(\mathrm{OH})_{3}+\mathrm{CaCl}_{2}+7 \mathrm{H}_{2} \mathrm{O}
$$

\section{Appendix B. Calculation of Average Error $e$}

The average error e within $y$ years is given by

$$
e=\sum_{t_{i}=1}^{y} \frac{\left|p_{f, s i m}\left(t_{i}\right)-p_{f, 0}\left(t_{i}\right)\right|}{y}
$$

where $y$ is an integer showing the number of exposure years, $p_{f, s i m}\left(t_{i}\right)$ is the probability of corrosion initiation at different time nodes $t_{i}$ after simplification and $p_{f, 0}\left(t_{i}\right)$ is the initial probability of corrosion initiation at different time nodes $t_{i}$ without any simplification.

\section{References}

1. Böhni, H. (Ed.) Corrosion in Reinforced Concrete Structures; Woodhead Publishing: Oxford, UK, 2005.

2. Bazant, Z.P. Physical model for steel corrosion in concrete sea structures-theory. ASCE J. Struct. Div. 1979, 105, 1137-1153.

3. Safehian, M.; Ramezanianpour, A.A. Prediction of RC structure service life from field long term chloride diffusion. Comput. Concr. 2015, 15, 589-606. [CrossRef]

4. Kwon, S.J.; Kim, S.C. Concrete mix design for service life of RC structures exposed to chloride attack. Comput. Concr. 2012, 10, 587-607. [CrossRef]

5. Ho, D.W.S.; Lewis, R.K. Carbonation of concrete and its prediction. Cem. Concr. Res. 1987, 17, 489-504. [CrossRef]

6. Demis, S.; Papadakis, V. Software-assisted comparative assessment of the effect of cement type on concrete carbonation and chloride ingress. Comput. Concr. 2012, 10, 391-407. [CrossRef]

7. Na, O.; Cai, X.; Xi, Y. Corrosion prediction with parallel finite element modeling for coupled hygro-chemo transport into concrete under chloride-rich environment. Materials 2017, 10, 350. [CrossRef] [PubMed]

8. Isteita, M.; Xi, Y. The effect of temperature variation on chloride penetration in concrete. Constr. Build. Mater. 2017, 156, 73-82. [CrossRef]

9. Homan, L.; Ababneh, A.; Xi, Y. The effect of moisture transport on chloride penetration in concrete. Constr. Build. Mater. 2016, 125, 1189-1195. [CrossRef]

10. Ozbolt, J.; Orsanic, F.; Balabanic, G.; Kuster, M. Modeling damage in concrete caused by corrosion of reinforcement: Coupled 3D FE model. Int. J. Fract. 2012, 178, 233-244. [CrossRef]

11. Ozbolt, J.; Balabanic, G.; Kuster, M. 3D Numerical modelling of steel corrosion in concrete structures. Corros. Sci. 2011, 53, 4166-4177. [CrossRef]

12. Cao, C.; Cheung, M.; Chan, B. Modelling of interaction between corrosion-induced concrete cover crack and steel corrosion rate. Corros. Sci. 2013, 69, 97-109. [CrossRef]

13. Pantazopoulou, S.; Papoulia, K. Modeling cover-cracking due to reinforcement corrosion in RC structures. J. Eng. Mech.-ASCE 2001, 127, 342-351. [CrossRef]

14. Zhu, X.; Zi, G. A 2D mechano-chemical model for the simulation of reinforcement corrosion and concrete damage. Constr. Build. Mater. 2017, 137, 330-344. [CrossRef]

15. Saassouh, B.; Lounis, Z. Probabilistic modeling of chloride-induced corrosion in concrete structures using first-and second-order reliability methods. Cem. Concr. Comp. 2012, 34, 1082-1093. [CrossRef] 
16. Shin, K.; Kim, J.; Lee, K. Probability-based durability design software for concrete structures subjected to chloride exposed environments. Comput. Concr. 2011, 8, 511-524. [CrossRef]

17. Kong, J.; Ababneh, A.; Frangopol, D.; Xi, Y. Reliability analysis of chloride penetration in saturated concrete. Probabl. Eng. Mech. 2002, 17, 305-315. [CrossRef]

18. Stewart, M.; Mullard, J. Spatial time-dependent reliability analysis of corrosion damage and the timing of first repair for RC structures. Eng. Struct. 2007, 29, 1457-1464. [CrossRef]

19. Stewart, M.; Suo, Q. Extent of spatially variable corrosion damage as an indicator of strength and time-dependent reliability of RC beams. Eng. Struct. 2009, 31, 198-207. [CrossRef]

20. Ryan, P.; O'Connor, A. Probabilistic analysis of the time to chloride induced corrosion for different self-compacting concretes. Constr. Build. Mater. 2013, 47, 1106-1116. [CrossRef]

21. Nogueira, C.; Leonel, E. Probabilistic models applied to safety assessment of reinforced concrete structures subjected to chloride ingress. Eng. Fail. Anal. 2013, 31, 76-89. [CrossRef]

22. Strauss, A.; Wendner, R.; Bergmeister, K.; Costa, C. Numerically and experimentally based reliability assessment of a concrete bridge subjected to chloride-induced deterioration. J. Infrastruct. Syst. 2012, 19, 166-175. [CrossRef]

23. Val, D.; Trapper, P. Probabilistic evaluation of initiation time of chloride-induced corrosion. Reliab. Eng. Syst. Saf. 2008, 93, 364-372. [CrossRef]

24. Saetta, A.; Scotta, R.; Vitaliani, R. Analysis of chloride diffusion into partially saturated concrete. ACI Mater. J. 1993, 90, 441-451.

25. Suo, Q.; Stewart, M. Corrosion cracking prediction updating of deteriorating RC structures using inspection information. Reliab. Eng. Syst. Saf. 2009, 94, 1340-1348. [CrossRef]

26. Bastidas-Arteaga, E.; Schoefs, F.; Stewart, M.; Wang, X. Influence of global warming on durability of corroding RC structures: A probabilistic approach. Eng. Struct. 2013, 51, 259-266. [CrossRef]

27. Duprat, F.; Vu, N.; Sellier, A. Accelerated carbonation tests for the probabilistic prediction of the durability of concrete structures. Constr. Build. Mater. 2014, 66, 597-605. [CrossRef]

28. Duprat, F.; Vu, N. Probabilistic threshold for the onset of carbonation-induced corrosion. Eur. J. Environ. Civ. Eng. 2013, 17, 478-495. [CrossRef]

29. Lollini, F.; Redaelli, E.; Bertolini, L. Analysis of the parameters affecting probabilistic predictions of initiation time for carbonation-induced corrosion of reinforced concrete structures. Mater. Corros. 2012, 63, 1059-1068. [CrossRef]

30. Mai-Nhu, J.; Sellier, A.; Duprat, F.; Rougeau, P.; Caprad, B.; Hyvert, N.; Francisco, P. Probabilistic approach for durable design of concrete cover: Application to carbonation. Eur. J. Environ. Civ. Eng. 2012, 16, $264-272$. [CrossRef]

31. Huang, T. The Experimental Research on the Interaction between Concrete Carbonation and Chloride Ingress under Loading. Master's Thesis, Zhejiang University, Hangzhou, China, 2013.

32. Zhu, X.J.; Zi, G.; Cao, Z.; Cheng, X. Combined effect of carbonation and chloride ingress in concrete. Constr. Build. Mater. 2016, 110, 369-380. [CrossRef]

33. Zhu, X.J.; Kim, S.; Kwak, D.; Bea, K.; Zi, G. Parametric analysis for the simultaneous carbonation and chloride ion penetration in reinforced con crete sections. J. Korea Inst. Struct. Maint. Insp. 2016, 20, 66-74.

34. Lee, M.; Jung, S.; Oh, B. Effects of carbonation on chloride penetration in concrete. ACI Mater. J. 2013, 110, 559-566. [CrossRef]

35. Backus, J.; Mcpolin, D.; Basheer, M.; Long, A.; Holmes, N. Exposure of mortars to cyclic chloride ingress and carbonation. Adv. Cem. Res. 2013, 25, 3-11. [CrossRef]

36. Tumidajski, P.; Chan, G. Effect of sulfate and carbon dioxide on chloride diffusivity. Cem. Concr. Res. 1996, 26, 551-556. [CrossRef]

37. Yoon, I. Simple approach to calculate chloride diffusivity of concrete considering carbonation. Comput. Concr. 2009, 6, 1-18. [CrossRef]

38. Yoon, I. Deterioration of concrete due to combined reaction of carbonation and chloride penetration: Experimental study. Key Eng. Mater. 2007, 348-349, 729-732. [CrossRef]

39. Yoon, I. Simple approach for computing chloride diffusivity of (non)carbonated concrete. Key Eng. Mater. 2008, 385-387, 281-284. [CrossRef]

40. Yuan, C.; Niu, D.; Luo, D. Effect of carbonation on chloride diffusion in fly ash concrete. Disaster Adv. 2012, $5,433-436$. 
41. Delnavaz, A.; Ramezanianpour, A. The assessment of carbonation effect on chloride diffusion in concrete based on artificial neural network model. Mag. Concr. Res. 2012, 64, 877-884. [CrossRef]

42. Ngala, V.; Page, C. Effects of carbonation on pore structure and diffusional properties of hydrated cement pastes. Cem. Concr. Res. 1997, 27, 995-1007. [CrossRef]

43. CEB-FIP. Fib Model Code for Concrete Structures; Wiley-VCH Verlag GmbH: Weinheim, Germany, 2010.

44. Zhang, S.; Zhao, B. Research on chloride ion diffusivity of concrete subjected to $\mathrm{CO}_{2}$ environment. Comput. Concr. 2015, 15, 589-606.

45. Zhu, X.J.; Zi, G.; Lee, W.; Kim, S.; Kong, J. Probabilistic analysis of reinforcement corrosion due to the combined action of carbonation and chloride ingress in concrete. Constr. Build. Mater. 2016, 124, 667-680. [CrossRef]

46. Ghanem, R.; Spanos, P. Stochastic Finite Elements: A Spectral Approach; Springer: New York, NY, USA, 1991; pp. 15-36.

47. Xiu, D. Numerical Methods for Stochastic Computations: A Spectral Method Approach; Princeton University Press: Princeton, NJ, USA, 1991; pp. 33-45.

48. Bazant, Z.P.; Liu, K. Random creep and shrinkage in structures: Sampling. J. Struct. Eng. ASCE 1985, 111, 1113-1134. [CrossRef]

49. Papadakis, V.; Vayenas, C.; Fardis, M. Fundamental modeling and experimental investigation of concrete carbonation. ACI Mater. J. 1991, 88, 363-373.

50. Papadakis, V.; Vayenas, C.; Fardis, M. Experimental investigation and mathematical modeling of the concrete carbonation problem. Chem. Eng. Sci. 1991, 46, 1333-1338. [CrossRef]

51. Angst, U.; Elsener, B.; Larsen, C.; Vennesland, Ø. Critical chloride content in reinforced concrete-A review. Cem. Concr. Res. 2009, 39, 1122-1138. [CrossRef]

52. Söylev, T.; François, R. Corrosion of reinforcement in relation to presence of defects at the interface between steel and concrete. J. Mater. Civ. Eng. 2005, 17, 447-455. [CrossRef]

53. Shi, J.; Ming, J. Influence of defects at the steel-mortar interface on the corrosion behaviour of steel. Constr. Build. Mater. 2017, 136, 118-125. [CrossRef]

54. Horne, T.; Richardson, I.; Brydson, R. Quantitative analysis of the microstructure of interfaces in steel reinforced concrete. Cem. Concr. Res. 2007, 37, 1613-1623. [CrossRef]

55. Angst, U.; Elsener, B.; Larsen, C.; Vennesland, Ø. Chloride induced reinforcement corrosion: Electrochemical monitoring of initiation stage and chloride threshold values. Corros. Sci. 2011, 53, 1451-1464. [CrossRef]

56. Zhang, R.; François, R.; Castel, A. Influence of steel-concrete interface defects owing to the top-bar effect on the chloride-induced corrosion of reinforcement. Mag. Concr. Res. 2011, 63, 773-781. [CrossRef] 